\title{
O CANTO DA INFORMÁTICA
}

Alfredo Magalhães

Para a contabilidade e gestão, como noutras árcas empresariais, a informática é essencial para o desempenho do exercício dessas actividades.

Há cerca de duas dezenas de anos quando uma empresa encarava a hipótese de adquirir um computador, a maioria das vezes era para fazer a contabilidade, e só depois se pensava em informatizar oulras tarefas.

Nesta nova revista do ISC $\Lambda$ P, reúno três pequenos textos que tentam esclarecer e ajudar os menos informados sobre novas tecnologias. Como grande parte das pessoas considera computador aquilo que se apresenta à frente dos olhos, o primeiro texto fala dos monitores. O segundo aborda as diferentes maneiras de estabelecer ligações do computador a equipamento periférico. Finalmente, o terceiro versa um assunto que deveria preocupar todos os docentes, que é a pureza da língua portugnesa.

\section{À frente dos nossos olhos}

Os monitores são o dispositivo informático mais importante (pelo menos o mais visível), logo após o processador. De facto são una porta que nos leva e traz informação e se coloca mesmo à frente dos nossos olhos horas a fio.

Não é de estranhar que muitos utilizadores os confundam com os próprios computadores. Já muitas vezes me têm pedido para arranjar um computador, mas somente com teclado e monitor... É aquilo que aparentemente tem utilidade! Talvez para fazer a vontade a estes minimalistas, BuLl Gates tenha lançado há pouco tempo atrás a ideia dos Ne1PC. E houve quem levasse isso a sério! 
Durante muitos anos os monitores foram variantes dos velhos tubos de raios catódicos (CRT) com uma frente de vidro recoberta de fósforo, onde os clectrões projectados provocam luminescência.

Os primeiros monitores cram de fósforo verde que deixavam rasto bem visível e feriam intensamente a vista. Mesmo os primeiros monitores coloridos que apareceram na década de setenta eram tão maus que muita gente preferia os monocromáticos...

Depois as coisas começaram a melhorar. Apareceram primeiro os de fósforo branco e os de âmbar, mais amigáveis para a vista, depois os de vidro anti-reflexo e baixa radiação, e finalmente os de ecrã plano.

Quanto ao tamanho (diagonal), temos monitores de 9", 14", 15", 17", 19" c 21". Os monocromáticos c os de 9" têm aplicaçõcs bastante reduzidas. Os de 14" quase desaparceram, indo os de 15" a caminho disso.

Como sc disse, a base de um monitor tradicional é o tubo com um canhão de electrões. No caso do monocromático, os electrões embatem contra a superfícic de fósforo branco $\mathrm{c}$, dependendo da intensidade, produzem imagens a preto e branco ou com gradações de cinzento. Um monitor a cores tem três canhões de electrões, cujos feixes vão excitar as pintas ou tiras de vermelho, verde ou azul (RGB) agrupadas em tríades no forro de fósforo do ecrã. Esses pontos são conhecidos por pixels, abreviatura do inglês picture elements. Iluminando-os com diferentes intensidades é possível gerar uma infinidade de cores.

Para evitar que os clectrões atinjam os pixels de forma desfocada é colocada em frente do tubo uma "máscara de sombra" que é uma placa de metal com furos. Uma alternativa é a solução Trinitron que usa uma grelha de aberturas ou seja uma série de fios verticais para isolar os pixels.

A qualidade de imagem mede-se pela quantidade de pontos ou pixels com que é possível traduzi-la e mostrá-la no ecrã. Estamos a falar em resolução. Mede-se em número de pixels na horizontal e de linhas na vertical. Quanto maior o seu número, melhor será a imagem. Por exemplo, 1024x768 significa 1024 pixels na horizontal em cada uma das 768 linhas. 
Nos monitores a cores, a resolução tem outros elementos: a distância entre ponto ou tira de cor numa tríade e outro da mesma cor na tríade seguinte ("dot pitch"). Essa distância é medida em milímetros. A maior parte dos monitores CRT do mercado têm distância entre pontos de $0,28 \mathrm{~mm}$ mas os mais recentes podem alcançar menos de $0,25 \mathrm{~mm}$, o que dá uma imagem muito mais fina.

Outro elemento a ter em conta é a velocidade de refrescamento ou varrimento dos pontos. Essa velocidade deve situar-se acima dos $70 \mathrm{~Hz}$ (setenta vezes por segundo) para não ser visivel ao olho humano. Velocidades de 80, 90 ou mesmo $100 \mathrm{~Hz}$ são vulgares nos monitores actuais e mais confortáveis para a vista.

Existem outro tipo de monitores baseados em tecnologias não CRT. Estamos a referir-nos aos monitores de plasma, aos de cristais líquidos (LCD) e aos TFT (thin film transistor). Estes últimos estão a invadir o mercado e a substituir com uma taxa impressionante os monitores de tubo. São constituídos por uma fina malha de transístores cmissores de luz, agrupando igualmente tríades de transístores para produção das três cores básicas.

Além da vantagem do espaço ocupado, que é muito menor no caso dos TFTs, há muito poucas razões que os tornem preferíveis aos tradicionais monitores. As distâncias de pontos ("dot pitch") andam em quase todos os modelos nos 0,28 ou mesmo acima dos $0,30 \mathrm{~mm}$ ! As frequências vão muito pouco acima dos $70 \mathrm{~Hz}$, excepto nos modelos mais caros, e introduziram-se novas características a ter em conta como o contraste ou o ângulo de visão...

Oulras tecnologias como os FED, em que cada pixel funciona como um minúsculo CRT c os electroluminescentes estão ainda em fase experimental. Um protótipo da Sony deste último tipo tem campos de utilização inesperados pois o vidro é substituído por um plástico fino, tornando possível enrolar ou dobrar o monitor! A Philips diz que tem pronta uma nova tecnologia para lançar nos próximos dois anos que promete revolucionar completamente o campo dos monitores ou televisões, pois a qualidade de imagem é muito para além daquilo que alguma vez possamos imaginar. Ficamos à espera. 


\section{Ligações}

A parte de trás de um computador normalmente é um emaranhado de fios das mais diversas cores e espessuras, que servem para ligar os periféricos à unidade central.

Além duma tomada redonda para o teclado e outra semelhante para o rato, todos os computadores, mesmo os mais antigos, trazem uma ou duas portas RS232C (os portátcis muitas vezes já não trazem nenhuma) e uma porla de impressora. Isto claro para além da alimentação e dos dispositivos de som como as colunas.

As portas de teclado e rato, muitas vezes conhecidas erradamente por PS/2, obedecem à norma curopeia DIN ou mini-DIN (o nome correcto) e eram designadas há três décadas como fichas Philips, por ser esta cmpresa que as lançou no mercado. A ficha do teclado actualmente distingue-se da do rato por os fabricantes adoptarem cores diferentes. Assim, a ficha do teclado é roxa enquanto a do rato verde.

Para resolver esta confusão de fichas e tomadas de aspecto e protocolos de comunicação diferentes, um grupo de empresas lançou uma nova especificação capaz de abranger todo o tipo de periféricos. Nascia assim o USB - Universal Serial Bus. Com a inclusão dessa interface nos sistemas operativos, nomeadamente o Windows, não só foi facilitado o tipo de ligação de periféricos, como também simplificada a sua complicada configuração - velocidade, paridade, número de bits, etc. É que o modelo USB é Pnp, isto é, pode ser reconhecido pelo computador e pode-se configurar sozinho, fornecendo inclusive alimentação de energia se o periférico necessitar.

Outra grande vantagem do USB é a velocidade de comunicações. Por exemplo, o RS232C não tem vclocidades na prática muito superiores a 38400 bps, muitas vezes não passa mesmo dos 9600 bps. O USB, por seu lado, pode trabalhar à velocidade baixa de 1,5 Mbps e à alta de 12 Mbps. Não tem comparação. Mas já surgiu no mercado uma nova definição de USB - o USB 2.0 - que na velocidade alta pode ir até aos 480 Mbps. Este último modelo, concebido originalmente pela Compaq, Intel, Microsoft e NEC, a que se juntaram depois HP, Lucent e Philips, só agora começa a estar mais divulgado, substituindo ou coexistindo com o irmão mais velho o USB 1.1. 
Um outro modelo cada vez mais falado é o FireWire ou IEEE 1394. Foi definido pela Apple há anos atrás para conexão de dispositivos digitais, nomeadamente câmaras de vídeo. Também cste interface ć usado em áudio profissional c mesmo em alguns discos rígidos externos ou outros periféricos de alta velocidade. A velocidade de transmissão chega aos $400 \mathrm{Mbps}$, portanto muito acima do USB I.I que surgiu no mercado depois.

A Apple conseguiu inovar mais uma vez ao introduzir um novo padrão (ILEE 1394b), o FireWire 800. A velocidade de transferência pode ir até aos $800 \mathrm{Mbps}$. Além disso, como é capaz de utilizar cabos de fibra óptica, os cabos podem alcançar 100 metros, contra os 4,5 metros do modelo anterior e os 5 metros do USB 2.0.

Resta falar na porta de impressora ou porta paralela, conhecida tecnicamente como modelo IEEE 1284. Este tipo de ligação foi desenvolvido pela Centronics c adoptado pela IBM cm 1981 e logo a seguir por outras cmpresas. É por isso que inicialmente cra conhecido como ligação Centronics.

Usa este modelo uma ficha delta de 25 pinos do lado do computador e uma ficha especial de 36 pinos do lado da impressora. O cabo é relativamente grosso e tecnicamente não deve ir além dos 7 metros.

Mais tarde, csta interface foi melhorado por proposta de vários fabricantes entre os quais a Intel, de modo a permitir comunicaçóes bidireccionais e assim ligar dispositivos como digitalizadores ("Scanners") ou discos Zip, entre outros. Este melhoramento reccbeu o nome de ECP (Enhaneed Capability Port) com capacidades de transferência da ordem de 4 Megabytes por segundo, por oposição ao modelo anterior que passou a chamar-se SPP (Single Parallel Port) e é unidireccional, só alcançando velocidades de 150 Kbytes por segundo. Mais recentemente, novo ajuste permitiu ir até aos 5 Megabytes por scgundo e recebeu o nome de EPP (Enhanced Parallel Port).

A maioria das impressoras mais recentes já não utiliza este tipo de ligação mas sim USB. É que, mesmo no modo ECP, os 4 Megabytes por segundo (32 Mbits/s) são bastante mais lentos que os $480 \mathrm{Mbps}$ do USB 2.0. Isto para não falar do cabo que é muito mais fino e com fichas muito pequenas para o USB, sendo o cabo paraleto um cabo grosso e com fichas grandes como se disse acima. 


\section{Sem Fios}

Mas o que parece estar na moda são as ligações sem fios. Começou com os infra-vermelhos para ligar o $\mathrm{PC}$ ou o portátil à impressora, depois vieram o rato e teclado sem fios. Agora, até já aparecem monitores que não precisam de cabos para se ligarem à unidade central.

No entanto, o maior campo de aplicação das ligações sem fios são as redes e acessos à Internet. No caso das redes, temos definidas três normas principais: a $802.11 \mathrm{~b}$, a $802.11 \mathrm{~g}$ e a $802.11 \mathrm{a}$. Além de pormenores técnicos que as distinguem, a principal diferença reside na velocidade de transmissão e consequentemente nos preços dos componentes. O modelo 802.11 b pode comunicar de $2 \mathrm{Mbps}$ a 11 Mbps ao passo que os dois outros referidos podem chegar aos 54 Mbps. De qualquer modo, ficam longe dos 100 Mbps correntes nas vulgares redes locais com fios.

Numa rede sem fios, também conhecida como WLAN e os seus componentes como WI-F1, precisamos de ter como ligações por rádio não só as placas de rede mas sobretudo os concentradores (HUBs). O problema principal reside nas interferêtncias. Em certos edifícios, o ferro da verga que compõe o cimento armado de colunas c placas é suficiente para colocar problemas de transmissão de dados.

Com as redes sem fio a avançarem rapidamente, começa a divulgar-se também o acesso à Internet sem fios mesmo em lugares públicos. Estes lugares com pontos de acesso à Internet são conhecidos pelo nome em inglês de hotspots. Existem, por exemplo, no Parque da Nações e Docas em Lisboa, em vários campos universitários, aeroportos, hospitais e agora até centros comcrciais.

Um levantamento recente encontrou na zona de Lisboa 1100 redes sem fios e 500 na área do Porto. A tendência é para alargar essa utilização a cada vez mais espaços.

\section{O dente azul}

Para comunicações entre computador e periféricos ou outros dispositivos electrónicos foi definida em 1998 pelo grupo de empresas 
que compunham a SIG uma norma a que foi dado o nome dum rei da Dinamarca, Bluetooth. A comunicação faz-se a 1 Mbps e a uma distância não superior a 10 metros.

Apesar disso, o Bluetooth já está largamente implantado em telemóveis e impressoras de última geração, bem como nos computadores portáteis. Com uma utilização generalizada podemos simplificar muitas operações rotineiras do nosso dia-a-dia. Vejamos alguns exemplos:

1. Ao chegar a casa com o seu telemóvel ligado e no bolso, a porta de casa reconhece-o, abrindo-se automaticamente e acendendo as luzes.

2. Ao fazer compras numa loja, o valor é descontado na sus conta bancária ao passar junto da registadora a funcionar com Bluetooth. Esta comunicou com o seu telemóvel, que passou a comunicação ao banco.

3. Chegou ao hotel. Na recepção reconhecen-no logo pelo nome, o seu número de quarto e a chave electrónica são transferidos para o seu PDA (aquelas agendas electrónicas muito em voga). Ao chegar ao quarto, a porta abre-se automaticamente.

De facto, o futuro está já aí à nossa espera. Dentro de pouco tempo, nem vamos imaginar como tínhamos paciência para tanta pequena tarefa que nos ocupava o nosso tempo sem qualquer utilidade aparente.

\section{A linguagem informática}

Desde há algumas décadas que está enraizada dentro da comunidade informática o uso indiscriminado e abusivo de termos em inglês. Evidentemente que muitas coisas se explicam e compreendem dado que os neologismos que se vão criando para nomear coisas ou factos que nascem na área das novas tecnologias nem sempre têm correspondência imediata na língua de Camões. Também é verdade que grande parte da literatura técnica mais actualizada se encontra en inglês, e quem lê ou traduz, a 
maior parte das vezes, não conhece ou não encontra sinónimos ná nossa língua.

Mas, após esta pequena introdução, direi que não compreendo que muitos termos em inglês circulem por aí quando existem palavras $\mathrm{em}$ português vernáculo para expressar o mesmo conceito.

Poder-se-á achar excessiva a minha preocupação por estas questões. Porém, além de me conhecer desde muito novo na luta pela língua portuguesa, expurgada de estrangeirismos, tive na FEUP professores (quase todos) que se preocupavam em encontrar sempre as palavras correctas na nossa língua para falarem de questões técnicas. Também estive dez anos como defensor do bom português e caçador de erros no Jornal de Notícias.

Muitas vezes, a utilização de termos estrangeiros radica na ignorância de quem fala ou escreve, tal como os emigrantes que vinham para a aldeia do interior fazer uma casa tipo maison com janelas tipo fenêtre. Li há cerca de três anos os apontamentos de um professor do ISEP que explicava o comando que procura uma cadeia de caracteres em UNIX e que devia coincidir com a cadeia de caracteres dada. Ele simplesmente dizia que a cadeia dada tinha que fazer match...

Nos anos 70 e 80 do século passado, época de grande expansão e popularização da informática, assistiu-se a outro fenómeno estranho. Foi o aportuguesamento de termos em inglês sem nenhuma razão válida. E ainda circulam por aí técnicos da velha guarda cue dilitam failes, printam mapas ou até que têm que preparar o targucte para o ano scguinte. Estes últimos merecem que se thes responda em castelhano: por supuesto!

Também, nessa altura e levados na onda do inglês, muitos desataram a pronunciar palavras portuguesíssimas com sotaque anglófono: interface, item, média, etc. O mais estranho é que esses termos, e outros mais que podia citar, são portugueses, de raiz latina, de onde vieram por via erudita, e foram os anglófonos que os vieram buscar às línguas latinas por não existirem nas próprias origens.

Um professor é um educador e a sua acção não se deve limitar ao campo restrito da matéria a leccionar. Todos nós temos nas nossas 
memórias bons professores que se distinguiram e nos marcaram por coisas que nem sempre tinham relação directa e exclusiva com a matéria que ensinavam. E depois, como dizia o poeta, "a minha pátria é a língua portuguesa..."

Para acabar deixem-me relatar uma história que me contaram recentemente. Numa vila do interior, tem um familiar meu uma quinta, onde com muita satisfação e algum proveito se dedica à agricultura nos tempos livres (hóbi, dirão os novos estrangeirados...).

Como vizinho tem uma pessoa radicado longos anos em França, ao ponto de esquecer parte da língua pátria. Este vizinho, por vezes, empresta do meu familiar um mini-tractor. Uma das últimas vezes, perante novo pedido da dita alfaia, o senhor teve esta tirada magnífica: "A machine vai arretar, por isso o senhor professor profite-a bem". E que a todos profite a lição que eu vou-me arretar por aqui... 